\title{
Effects of Pyrolysis Conditions and Feedstocks on the Properties and Gasification Reactivity of Charcoal from Woodchips
}

\author{
Aekjuthon Phounglamcheik,* Liang Wang, Henrik Romar, Norbert Kienzl, Markus Broström, \\ Kerstin Ramser, Øyvind Skreiberg, and Kentaro Umeki
}

Cite This: Energy Fuels 2020, 34, 8353-8365

Read Online

ABSTRACT: Pyrolysis conditions in charcoal production affect yields, properties, and further use of charcoal. Reactivity is a critical property when using charcoal as an alternative to fossil coal and coke, as fuel or reductant, in different industrial processes. This work aimed to obtain a holistic understanding of the effects of pyrolysis conditions on the reactivity of charcoal. Notably, this study focuses on the complex effects that appear when producing charcoal from large biomass particles in comparison with the literature on pulverized biomass. Charcoals were produced from woodchips under a variety of pyrolysis conditions (heating rate, temperature, reaction gas, type of biomass, and bio-oil embedding). Gasification reactivity of produced charcoal was determined through thermogravimetric analysis under isothermal conditions of $850{ }^{\circ} \mathrm{C}$ and $20 \%$ of $\mathrm{CO}_{2}$. The charcoals were characterized for the elemental composition, specific surface area, pore volume and distribution, and carbon structure. The analysis results were used to elucidate the relationship between the pyrolysis conditions and the reactivity. Heating rate and temperature were the most influential pyrolysis parameters affecting charcoal reactivity, followed by the reaction gas and bio-oil embedding. The effects of these pyrolysis conditions on charcoal reactivity could primarily be explained by the difference in the meso- and macropore volume and the size and structural order of aromatic clusters. The lower reactivity of slow pyrolysis charcoals also coincided with their lower catalytic inorganic content. The reactivity difference between spruce and birch charcoals appears to be mainly caused by the difference in catalytically active inorganic elements. Contrary to pyrolysis of pulverized biomass, a low heating rate produced a higher specific surface area compared with a high heating rate. Furthermore, the porous structure and the reactivity of charcoal produced from woodchips were influenced when the secondary char formation was promoted, which cannot be observed in pyrolysis of pulverized biomass.

\section{INTRODUCTION}

Charcoal from slow pyrolysis of biomass is a promising substitute for fossil coal and coke. For industrial applications such as cofiring power plants, ${ }^{1,2}$ syngas production, ${ }^{3}$ and metallurgical processes, ${ }^{4,5}$ there is a significant interest in replacing fossil fuels and/or reductants with biomass and charcoal. It was recently proposed to replace pulverized coal injection in blast furnaces with pulverized charcoal. ${ }^{4-6}$ However, this application has strict requirements for charcoal, that is, grindability, fixed carbon content, heating value, and reactivity. ${ }^{4}$ Through optimizing pyrolysis process conditions, the charcoal properties can be modified to meet requests for specific final applications. The main elementary $(\mathrm{C}, \mathrm{H}, \mathrm{N}$, and $\mathrm{O})$ composition and the heating value of charcoal are similar to those of pulverized coal at a pyrolysis temperature above 500 ${ }^{\circ} \mathrm{C}$, and its yield typically decreases by one-third compared to that at $300{ }^{\circ} \mathrm{C}$, i.e., torrefaction conditions. ${ }^{4,7,8}$ Our previous study demonstrated a considerably higher charcoal yield by promoting secondary char formation, that is, by purging the reactor with $\mathrm{CO}_{2}$ and embedding bio-oil on the external and partly internal surfaces of woodchips, without any drastic effects on elementary compositions or heating values. ${ }^{7}$ Nonetheless, the reactivity of charcoal requires closer attention. The reactivity of charcoal is an essential design parameter that influences the capacity of thermochemical reactors regarding combustion and gasification., 10 High reactivity is preferred when a greater specific capacity of the reactors is of primary concern. In existing industrial facilities, however, the process is often optimized for the reactivity of the current fuel in order to achieve the desired product quality. Thus, a change in the fuel to one with a significantly different reactivity may lead to costly process modification. It would, therefore, be beneficial if we could optimize pyrolysis processes and achieve the targeted reactivity specified by the charcoal users.

Previous studies ${ }^{11-14}$ showed that charcoal reactivity is mainly affected by three parameters: (i) the content and composition of inorganic elements, (ii) the physical structure, that is, the specific surface area and pore-size distribution, and (iii) the content of functional groups and chemical structure of the carbon matrix. Alkali and alkaline earth metals (e.g., $\mathrm{Na}, \mathrm{K}$, $\mathrm{Ca}$, and $\mathrm{Mg}$ ) are well-known for their catalytic effects on the conversion of charcoal via the oxygen transfer cycle. ${ }^{15-19}$ On

Received: February 24, 2020

Revised: May 18, 2020

Published: May 26, 2020 
the other hand, $\mathrm{Cl}, \mathrm{S}, \mathrm{P}$, and $\mathrm{Si}$ might react with alkali and alkali metals, which reduces the availability of the catalytic metals and lowers their effect. ${ }^{20,21}$ The particle size and pore size also affect the reactivity of charcoal, which can considerably influence the diffusion rate and thereby the local concentration of reactant gases available to react with solid carbon. ${ }^{11}$ Meanwhile, the internal surface area and chemical structures, for example, the content of carbon edges, defects, and functional groups, represent a fraction of the active sites on the accessible solid surface. These parameters are strongly influenced by the type of biomass and pyrolysis conditions. The production of charcoal from large biomass particles, for example, woodchips and pellets, is more viable compared to biomass powder. This is not only because of the ease of particle processing but also because large particles give a higher charcoal yield than small particles. ${ }^{22}$ Thus, it is essential to elaborate on the pyrolysis of large particles, the focus on which is somewhat limited in the literature.

The content of total and certain inorganic elements of biomass materials can be significantly different. In general, agricultural biomass contains a much higher concentration of inorganic elements compared to woody biomass. ${ }^{23}$ High inorganic content in agricultural biomass not only results in complicated catalytic activity but also in technical challenges because of the high ash amount and the degree of slag formation. ${ }^{21}$ Thus, woody biomass is preferred when it comes to industrial applications. However, different types and parts of forestry biomass, for example, bark and forest residues, also give significant variations. ${ }^{24} \mathrm{Ca}$ is the most common inherent inorganic element in woody biomass, usually followed by varying contents of $\mathrm{K}, \mathrm{Si}, \mathrm{Mg}$, and $\mathrm{P}$ and a trace amount of $\mathrm{S}$ and $\mathrm{Cl}$. Additionally, sand and clay minerals introduced during fuel processing may alter the overall fuel composition. ${ }^{25}$ In addition, there are considerable differences in woody biomasses regarding the content of main biological components such as cellulose, hemicellulose, and lignin. The presence and interactions of these components during the thermal conversion process will also affect the yield and property of produced charcoal. ${ }^{26}$ DeGroot and Shafizadeh ${ }^{27}$ reported that the gasification reactivity of cottonwood (softwood) charcoal was significantly higher than that of Douglas fir (hardwood) charcoal. The distinct differences in morphology between softwood and hardwood charcoal could partially explain the difference in reactivity. However, experimental investigations of the correlation between morphology and reactivity of softwood and hardwood charcoal are limited. Instead, the literature only implied that the catalytic effect of inorganic content was the main reason for the difference in reactivity of the two wood species.

The heating rate has a dramatic effect on the morphological and chemical structure of charcoals. Charcoal obtained from a higher heating rate (HHR) was reported to be more reactive in gasification, ${ }^{12,28-30}$ although there is no consensus for the reasons. HHR charcoal from wood powders ${ }^{29,31,32}$ tends to have a higher specific surface area, while large particles exhibit opposite trends during pyrolysis. ${ }^{12,30}$ Heating rates also affect the proportion of micropores $\left(d_{\text {pore }}<2 \mathrm{~nm}\right)$, mesopores $(2 \mathrm{~nm}$ $\left.<d_{\text {pore }}<50 \mathrm{~nm}\right)$, and macropores $\left(d_{\text {pore }}>50 \mathrm{~nm}\right) .{ }^{33}$ At a slow heating rate, that is, $\leq 100{ }^{\circ} \mathrm{C} \mathrm{min}^{-1}$, volatiles release gently from biomass with no major change in morphology. ${ }^{30,34}$ Meanwhile, a high heating rate leads to charcoal with larger cavities and a high degree of meso- and macropore structures because the rapid release of volatiles results in overpressure, rupture, and coalescence of pores. ${ }^{30,34}$ According to the review by $\mathrm{Di}$ Blasi, ${ }^{9}$ mesopores and macropores are major contributors to the reactive surface area, while the less accessible micropores barely participate in the reaction. The heating rate also affects the elemental composition and functional groups of charcoal, regardless of the particle size of the feedstock. A larger amount of oxygen functional groups and lower carbon content are normally observed in HHR charcoals. $^{32,35}$ This is simply explained by a shorter devolatilization time. ${ }^{36,37}$ Besides higher carbon and lower volatile contents, inorganic content was reported to be lower for low heating rate charcoal. ${ }^{30}$ This may be because the long retention time at high temperatures provides enough time for inorganic compounds to be released. However, this issue has not been clearly elaborated in the literature.

Besides the heating rate, a high pyrolysis temperature affects the surface area and the chemical structure of charcoal. Charcoal produced under high temperature has a typically larger specific surface area. ${ }^{32,38-40}$ However, the specific surface area of charcoal changes slightly or even decreases at a temperature above $800{ }^{\circ} \mathrm{C}$ because of structural ordering, commonly known as thermal annealing and pore coalescence. ${ }^{32,39,40}$ Higher temperatures also promote the structural ordering of charcoal, resulting in larger aromatic ring clusters. $^{33,41}$ According to advanced characterization techniques, the literature agrees that a high pyrolysis temperature promotes the loss of functional groups and the growth of aromatic ring systems. ${ }^{10,33,42-46}$ Although some inorganic elements such as $\mathrm{K}$ might start to release at sufficiently high pyrolysis temperatures, previous studies ${ }^{47-51}$ have shown that the release of other active inorganic elements, especially $\mathrm{Ca}$, $\mathrm{Mg}$, and $\mathrm{Si}$, is very slight and even negligible below $900{ }^{\circ} \mathrm{C}$ during the thermal conversion of woody biomass. Therefore, a certain amount of inorganic elements retained in charcoal can play a catalytic role, affecting its reactivity.

Secondary char formation may also affect the reactivity of charcoal. Among the limited attention on this topic, AncaCouce and coworkers ${ }^{51}$ conducted pyrolysis experiments that enhanced secondary char formation by varying the initial mass ( $10 \mathrm{mg}$ to $100 \mathrm{~g}$ ), particle size $(0.2 \mathrm{~mm}$ to $3 \mathrm{~cm})$, and bed type (thermogravimetric analysis (TGA) and fixed bed reactor). The results showed a significant reduction in charcoal reactivity when the secondary reactions were promoted. However, charcoal reactivity may behave differently when different methods are applied to promote secondary char formation. In our previous work, ${ }^{7}$ we embedded woodchips with recovered bio-oil from pyrolysis to increase secondary char formation. We also found that the pyrolysis of large particles under $\mathrm{CO}_{2}$ influences secondary char formation. ${ }^{7}$ The effects of these techniques on charcoal reactivity have not been elaborated in the literature.

There is a need to increase the understanding of the pyrolysis of large biomass particles. This has not been elaborated in the literature as much as the pyrolysis of biomass powder. The main objective of this work is to increase the understanding of how charcoal properties and reactivity change under different pyrolysis conditions, that is, heating rate, temperature, and biomass types. The second objective is to measure the reactivity variation of charcoal produced from pyrolysis methods applied to increase the yield in our previous work, ${ }^{7}$ that is, pyrolysis of bio-oil-embedded woodchips and purging with $\mathrm{CO}_{2}$. TGA was carried out under isothermal conditions after rapid heating to determine the intrinsic 
Table 1. Production Conditions of Charcoal Samples

\begin{tabular}{|c|c|c|c|c|c|}
\hline sample ID & raw material & heating rate & temperature $\left({ }^{\circ} \mathrm{C}\right)$ & purge gas & charcoal yield (\%, mass) \\
\hline S500N2R & spruce & rapid & 500 & $\mathrm{~N}_{2}$ & $22.5( \pm 0.4)$ \\
\hline S600N2R & spruce & rapid & 600 & $\mathrm{~N}_{2}$ & $18.5( \pm 0.7)$ \\
\hline S700N2R & spruce & rapid & 700 & $\mathrm{~N}_{2}$ & $17.9( \pm 0.5)$ \\
\hline S700N2S & spruce & slow & 700 & $\mathrm{~N}_{2}$ & $23.0( \pm 0.4)$ \\
\hline S700CO2R & spruce & rapid & 700 & $\mathrm{CO}_{2}$ & $17.8( \pm 0.5)$ \\
\hline S700CO2S & spruce & slow & 700 & $\mathrm{CO}_{2}$ & $27.6( \pm 0.5)$ \\
\hline SBO700N2R & spruce $+20 \%$ bio-oil & rapid & 700 & $\mathrm{~N}_{2}$ & $16.2( \pm 1.4)$ \\
\hline SBO700N2S & spruce $+20 \%$ bio-oil & slow & 700 & $\mathrm{~N}_{2}$ & $29.3( \pm 0.7)$ \\
\hline B700N2R & birch & rapid & 700 & $\mathrm{~N}_{2}$ & $15.0( \pm 0.4)$ \\
\hline $\mathrm{B} 700 \mathrm{CO} 2 \mathrm{R}$ & birch & rapid & 700 & $\mathrm{CO}_{2}$ & $15.1( \pm 0.2)$ \\
\hline B $700 \mathrm{~N} 2 \mathrm{~S}$ & birch & slow & 700 & $\mathrm{~N}_{2}$ & $18.4( \pm 0.4)$ \\
\hline
\end{tabular}

gasification reactivity of charcoals. Properties of charcoals, such as elemental composition, inorganic content and composition, pore structure, and carbon structure, were measured in order to interpret the relationship between pyrolysis parameters and reactivity.

\section{EXPERIMENTAL METHODS}

2.1. Preparation of Charcoal Samples. The charcoal samples in this study were prepared in a macro-thermogravimetric (macro-TG) reactor, Figure $\mathrm{S} 1$ in the Supporting Information, under various conditions. A detailed description of the preparation methods for the charcoal can be found in the Supporting Information and the previous study. ${ }^{7}$ The pyrolysis parameters in this study include the heating rate (isothermal conditions and slow heating at $3{ }^{\circ} \mathrm{C} \mathrm{min}^{-1}$ ), temperature $\left(500,600\right.$, and $\left.700{ }^{\circ} \mathrm{C}\right)$, reaction gas $\left(\mathrm{N}_{2}\right.$ and $\left.\mathrm{CO}_{2}\right)$, type of biomass (spruce and birch), and bio-oil embedding on woodchips. All charcoals were ground in a mortar and sieved to a sieve size below $75 \mu \mathrm{m}$. The samples were then divided into eight representative samples using a Retsch PT100 sample divider. Table 1 shows a summary of the pyrolysis conditions and the mass yield of the charcoals.

An ultimate analysis of the charcoal was carried out with EA3000, a CHNS-O elemental analyzer from Eurovector Srl. The determination of CHN was measured according to DIN 51732. The oxygen content was measured separately in the same analyzer using silver capsules injected into the reactor held at $1070{ }^{\circ} \mathrm{C}$, which contained pure helium and was packed with nickel-plated carbon. Oxygen content was then determined by the content of $\mathrm{CO}$ in the gas products by means of gas chromatography and thermal conductivity. Table 2 shows the ultimate analysis of the charcoal samples.

The inorganic elemental composition was analyzed using inductively coupled plasma optical emission spectrometry (ICPOES) after microwave-assisted pressurized acid digestion. A Multiwave 3000 microwave system (Anton Paar, Graz, Austria) was used

Table 2. Ultimate Analysis of Charcoal Samples (Dry Mass Basis)

$\begin{array}{lcccc}\text { sample ID } & \mathrm{C}(\%) & \mathrm{H}(\%) & \mathrm{N}(\%) & \mathrm{O}(\%) \\ \text { S500N2R } & 84.0 & 3.0 & <0.3 & 9.4 \\ \text { S600N2R } & 89.7 & 2.3 & <0.3 & 5.3 \\ \text { S700N2R } & 90.3 & 1.6 & 0.3 & 3.4 \\ \text { S700N2S } & 92.1 & 1.8 & 0.4 & 3.5 \\ \text { S700CO2R } & 89.8 & 1.5 & 0.3 & 3.8 \\ \text { S700CO2S } & 91.4 & 1.6 & 0.4 & 3.7 \\ \text { SBO700N2R } & 89.9 & 1.7 & 0.3 & 3.8 \\ \text { SBO700N2S } & 91.7 & 1.6 & 0.4 & 3.4 \\ \text { B700N2R } & 90.2 & 1.7 & 0.5 & 3.7 \\ \text { B700CO2R } & 90.4 & 1.6 & 0.5 & 3.6 \\ \text { B700N2S } & 91.7 & 1.6 & 0.5 & 5.1\end{array}$

for digestion. Each material was analyzed in duplicate by digesting around $20 \mathrm{mg}$ of charcoal with $7 \mathrm{~mL}$ of concentrated nitric acid, 0.2 $\mathrm{mL}$ of hydrofluoric acid, $0.2 \mathrm{~mL}$ of hydrochloric acid, and $0.2 \mathrm{~mL}$ of $\mathrm{HClO}_{4}$ (Carl Roth, Karlsruhe, Germany). The temperature was ramped to $195{ }^{\circ} \mathrm{C}$ within $15 \mathrm{~min}$ with the application of $1500 \mathrm{~W}$ of power, followed by a dwell time of $25 \mathrm{~min}$ at $195{ }^{\circ} \mathrm{C}$. The digested samples were further diluted to $14 \mathrm{~mL}$ with deionized water. The ICP-OES system was an Arcos SOP by Spectro (Kleve, Germany). Sample blanks and spikes were included in all preparation procedures. Certified reference material NCS DC 73348 "Bush Branches and Leaves" (China National Analysis Centre for Iron and Steel, Beijing) was used for quality control. The most relevant inorganic compositions are shown in Table S3 in the Supporting Information.

2.2. Gasification Reactivity. The charcoal gasification reactivity was measured using a thermogravimetric analyzer, Q5000IR, by TA Instruments. Around $1 \mathrm{mg}$ of the sample was loaded and spread on the bottom of a platinum pan. A gas mixture of $\mathrm{N}_{2}$ and $\mathrm{CO}_{2}$ was fed horizontally into a furnace as a reaction gas with a volumetric ratio of 80 and $20 \%$, respectively. The flow rate of the reaction gas was $50 \mathrm{~mL}$ $\mathrm{min}^{-1}$ in the standard state (i.e., $25{ }^{\circ} \mathrm{C}$ and $10^{5} \mathrm{~Pa}$ ). Prior to the experiments, the sample and the furnace were purged with the reaction gas for $30 \mathrm{~min}$. The sample was then heated to $850{ }^{\circ} \mathrm{C}$ at a heating rate of $500{ }^{\circ} \mathrm{C} \mathrm{min}-1$ to mimic the high heating rate of industrial processes. The sample was held at $850^{\circ} \mathrm{C}$, and the change in sample mass was measured for $30 \mathrm{~min}$. All charcoal samples were analyzed with two repetitions.

The thermogravimetric curves displayed a mass loss because of both devolatilization and gasification, as shown in Figure S2 in the Supporting Information. In order to determine the gasification reactivity, the initial mass $\left(m_{0}\right)$ was defined as the weight monitored at the end of the devolatilization phase (details are provided in the Supporting Information, Figure S2). Solid residue mass $(m)$ was the weight monitored during gasification under isothermal conditions, and charcoal conversion $(X)$ was calculated using

$$
X=\frac{m_{0}-m}{m_{0}}
$$

The intrinsic reactivity of the charcoals in this work is represented by the initial rate constant $\left(k_{\text {ini }}\right)$. After considering various models, the data were fitted by the random pore model to determine the rate constant at the conversion up to the minimum conversion that appeared after $30 \mathrm{~min}$ of gasification in the experimental data $\left(X_{\min }=\right.$ $0.25)$. The integral form of the random pore $\operatorname{model}^{52}$ is

$$
\left(\frac{2}{\psi}\right) \cdot[\sqrt{1-\psi \cdot \ln (1-X)}-1]=k_{\mathrm{ini}} \cdot t
$$

The structure parameter, $\psi$, was estimated from the experimental data using the reaction time at $X=0.25$ in the following expression

$$
\frac{[\sqrt{1-\psi \cdot \ln (1-X)}-1]}{[\sqrt{1-\psi \cdot \ln (1-0.25)}-1]}=\frac{t}{t_{X=0.25}}
$$


Examples of data fitting can be found in the Supporting Information, Figure S3.

2.3. Nitrogen Adsorption. The specific surface area, specific pore volume, and pore-size distribution of the charcoals were determined using an $\mathrm{N}_{2}$ adsorption method with a Micromeritics ASAP 2020 analyzer. Before the measurements, around $200 \mathrm{mg}$ of the sample was degassed at low pressures $(0.27 \mathrm{~Pa})$ and high temperatures $\left(140{ }^{\circ} \mathrm{C}\right)$ for $180 \mathrm{~min}$. Adsorption isotherms were obtained by immersing sample tubes in liquid nitrogen $\left(-197{ }^{\circ} \mathrm{C}\right)$ to obtain isothermal conditions. Nitrogen was added to the samples in small increases, and the resulting isotherms were obtained. The specific surface area and specific pore volume were calculated from adsorption isotherms according to the Brunauer-Emmett-Teller (BET) method. ${ }^{53}$ Poresize distribution was calculated using the Barrett-Joyner-Halenda (BJH) algorithm ${ }^{54}$ and the density functional theory (DFT) function. ${ }^{55}$ This method divides pore size into three different ranges, namely, micropore $(<2 \mathrm{~nm})$, mesopore $(2-50 \mathrm{~nm})$, and macropore $(>50 \mathrm{~nm})$. Examples of adsorption isotherms are provided in the Supporting Information, Figure S4.

2.4. Raman Spectroscopy. Raman spectroscopy was used to analyze the molecular structure and morphology of the charcoals. Raman spectra were collected using an inverted microscope (IX71, Olympus, Japan) coupled to a spectrometer (Shamrock 303i, Andor Technology, Ireland). A DPSS $532 \mathrm{~nm}$ was used as an excitation laser (Altechna, Azpect Photonics AB, Södertälje, Sweden). The laser was operated at $6 \mathrm{~mW}$. Spectra were collected from five different spots for each sample with $120 \mathrm{~s}$ of exposure time. All spectra were analyzed between 1100 and $1800 \mathrm{~cm}^{-1}$. Cosmic ray spikes were removed using the method provided by Schulze and Turner ${ }^{56}$ and the spectra were smoothed using a Savitzky and Golay filter. ${ }^{57}$ The fluorescence signal was eliminated by baseline subtraction, according to Cao et al. ${ }^{58}$ All spectra were normalized using a maximum intensity of around 1590 $\mathrm{cm}^{-1}$ as the reference. The intensity values of the peaks at around 1350 and $1590 \mathrm{~cm}^{-1}$ were taken to calculate intensity ratios.

Raman spectra of amorphous carbons are usually deconvoluted into several bands to improve fitting. A variety of deconvolution methods have been proposed in the literature. ${ }^{42,59-64}$ However, the number of band assignments and band shapes can easily influence the outcome of the result, leading to overprediction. Thus, Raman deconvolution needs to be carefully performed in a systematic procedure in order to obtain meaningful results. Here, only three Gaussian bands were assigned to the relevant Raman bands that appeared in the spectra, that is, D band at $1350 \mathrm{~cm}^{-1}$, G band at 1590 $\mathrm{cm}^{-1}$, and $\mathrm{V}$ band at a valley around $1450 \mathrm{~cm}^{-1}$. The band assignment was performed by implementing the peak fit function ${ }^{65}$ in MATLAB. The detailed procedure and an example of Raman deconvolution are provided in the Supporting Information, Figure S5.

\section{RESULTS AND DISCUSSION}

3.1. Porous Structure and Chemical Properties of Charcoals. Table S4 in the Supporting Information summarizes the porous structure of the charcoal samples measured by $\mathrm{N}_{2}$ adsorption. The results show the specific surface area, pore volume, and pore-size distribution of the charcoal samples. The charcoals have specific surface areas from 202 to $452 \mathrm{~m}^{2} \mathrm{~g}^{-1}$. The differences between the specific pore volume calculated from BET and BJH-DFT (i.e., the summation of pore-size distribution) are lower than $1 \%$. The pores were mostly distributed in the range of microscale $\left(d_{\text {pore }}\right.$ $<2 \mathrm{~nm}$ ) with $80-98 \%$ of the total pore volume. The specific surface area and micropore volume generally increased with pyrolysis temperature but with a large variation because of the change of other pyrolysis parameters. In general, charcoals produced at a low heating rate have a high surface area. The surface area of spruce charcoals slightly increased using $\mathrm{CO}_{2}$ as a reaction gas but this effect did not appear for birch ones. Bio- oil embedding gave relatively low and no consistent effect on the surface area of charcoals.

According to the ultimate analysis (Table 2), the charcoals contain a relatively high carbon content, between 84.0 and $92.1 \%$, and low oxygen, hydrogen, and nitrogen content. As reported in Table S3, the total inorganic content varied between 5034 and $12,587 \mathrm{mg} \mathrm{kg}^{-1}$. Ca and $\mathrm{K}$ are the most dominant inorganic elements, followed by $\mathrm{Si}, \mathrm{Mg}$, and $\mathrm{P}$. Concentrations of $\mathrm{Na}$ and $\mathrm{S}$ are very low and therefore may not influence the reactivity of charcoal significantly. According to the ternary phase diagram for the $\mathrm{K}-\mathrm{Ca}-\mathrm{Si}$ system shown in Figure S6 (the Supporting Information), the inorganic compositions of the studied charcoals remain in the upper left area of the diagram, where potassium silicate formation should be limited even at the gasification temperature applied in the current work. Ca carbonate and $\mathrm{K}-\mathrm{Ca}$ carbonates tend to form and affect the conversion of charcoal during the gasification.

The Raman spectra showed two overlapping peaks with maximum intensities of around 1350 and $1590 \mathrm{~cm}^{-1}$ (Figure S5 in the Supporting Information). These two peaks are commonly referred to as the $\mathrm{D}$ and $\mathrm{G}$ bands. ${ }^{66-68}$ In amorphous carbon, the $G$ band is related to the motion of carbon $\mathrm{sp}^{2}$ atoms, including both rings and chains. The $\mathrm{D}$ band is proportional to the amount of large aromatic clusters (>six fused rings $).{ }^{69}$ The intensity ratio of the raw spectra, $I_{\mathrm{D}} / I_{\mathrm{G}}$, has been introduced to indicate the amount of large aromatic clusters in amorphous carbon. The higher the value of the $I_{\mathrm{D}} /$ $I_{\mathrm{G}}$ ratio, the higher the amount of large aromatic clusters in the charcoal. Table 3 summarizes the $I_{\mathrm{D}} / I_{\mathrm{G}}$ ratios determined from

Table 3. $I_{\mathrm{D}} / I_{\mathrm{G}}$ Ratios of Charcoal Samples

\begin{tabular}{lccc}
\multicolumn{1}{c}{ sample } & $I_{\mathrm{D}} / I_{\mathrm{G}}(-)$ & $\mathrm{FWHM}_{\mathrm{D}}\left(\mathrm{cm}^{-1}\right)$ & $\mathrm{FWHM}_{\mathrm{G}}\left(\mathrm{cm}^{-1}\right)$ \\
S500N2R & $0.51( \pm 0.045)$ & $214( \pm 5.103)$ & $80( \pm 3.860)$ \\
S600N2R & $0.55( \pm 0.016)$ & $207( \pm 3.730)$ & $117( \pm 1.180)$ \\
S700N2R & $0.75( \pm 0.031)$ & $187( \pm 2.640)$ & $82( \pm 5.340)$ \\
S700N2S & $0.75( \pm 0.023)$ & $168( \pm 2.217)$ & $78( \pm 2.540)$ \\
S700CO2R & $0.76( \pm 0.035)$ & $186( \pm 3.200)$ & $83( \pm 5.340)$ \\
S700CO2S & $0.77( \pm 0.052)$ & $173( \pm 3.244)$ & $76( \pm 7.730)$ \\
SBO700N2R & $0.73( \pm 0.006)$ & $191( \pm 4.420)$ & $77( \pm 8.990)$ \\
SBO700N2S & $0.74( \pm 0.027)$ & $182( \pm 0.900)$ & $70( \pm 0.940)$ \\
B700N2R & $0.73( \pm 0.034)$ & $191( \pm 5.260)$ & $79( \pm 9.110)$ \\
B700CO2R & $0.74( \pm 0.018)$ & $189( \pm 5.760)$ & $71( \pm 13.070)$ \\
B700N2S & $0.74( \pm 0.013)$ & $186( \pm 2.420)$ & $77( \pm 5.490)$ \\
\hline
\end{tabular}

the charcoals. Although the $I_{\mathrm{D}} / I_{\mathrm{G}}$ ratio clearly distinguishes the carbon structure of the charcoals from different pyrolysis temperatures, it does not show significant differences among charcoals produced at $700{ }^{\circ} \mathrm{C}$. Thus, information from the deconvolution of the Raman spectra was used. Table 3 also shows the full width at half-maximum (FWHM) of the D and $G$ peaks. The decrease in the FWHM of the D band corresponds to the higher order of the carbon structure. ${ }^{70}$

3.2. Effect of Pyrolysis Conditions on Gasification Reactivity. 3.2.1. Pyrolysis Temperature. The charcoals produced from isothermal pyrolysis were used to study the effect of pyrolysis temperature on the reactivity. It should be noted that in the experiments under isothermal conditions, different pyrolysis temperatures also mean different heating rates of the woodchips. This is because the heat flux to the particles is proportional to the temperature difference between the particle surface and the surrounding environment. A higher pyrolysis temperature generally gives a more substantial 
difference between the initial temperature of the woodchips and the macro-TG reactor setpoint. This large temperature difference results in an higher heating rate of the woodchips, which affects their pyrolysis behaviors and properties and gasification reactivity of produced charcoals. Figure 1 shows

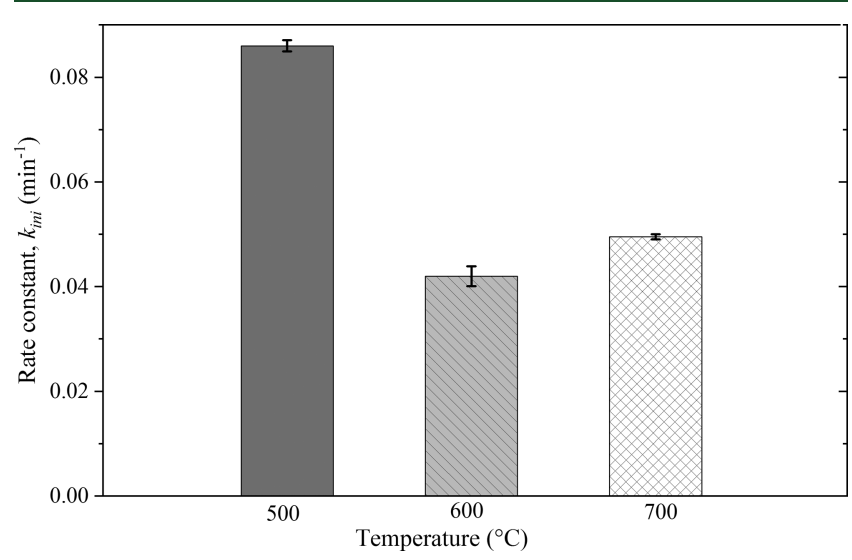

Figure 1. Rate constant of the charcoals produced from isothermal pyrolysis at various temperatures. The error bars are standard deviation obtained from two repetitions of each experimental point.

the gasification rate constant $\left(k_{\text {ini }}\right)$ of charcoals produced from spruce under isothermal pyrolysis in $\mathrm{N}_{2}$. The rate constant significantly decreased when the pyrolysis temperature increased from 500 to $600{ }^{\circ} \mathrm{C}$; the $p$-value was 0.0005 (a $p$ value lower than 0.05 implies that the difference is statistically significant with $95 \%$ confidence). However, the rate constant of the charcoal obtained at $600{ }^{\circ} \mathrm{C}$ was slightly lower than the charcoal obtained at $700{ }^{\circ} \mathrm{C}$ ( $p$-value: 0.037 ), which could be caused by the higher heating rate at $700{ }^{\circ} \mathrm{C}$.

Figure 2 shows the total pore volume and pore-size distribution of the charcoals at various temperatures. Total

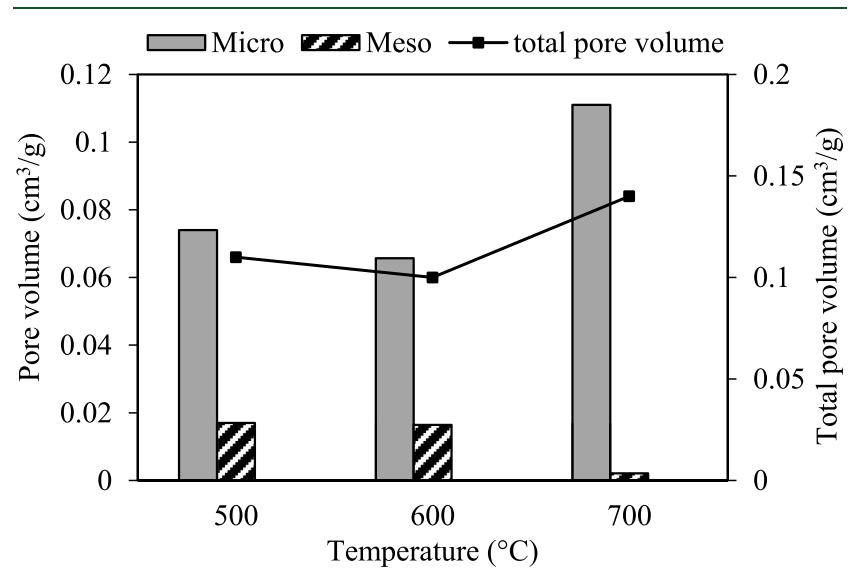

Figure 2. Specific pore volume and pore-size distribution of the charcoals produced from isothermal pyrolysis at various temperatures.

pore volume increased when the temperature increased from 600 to $700{ }^{\circ} \mathrm{C}$. However, the increase in the pore volume of the charcoals was mainly due to the increase in micropore volume. The increased micropore volume may correspond to a higher rate of volatile release during pyrolysis at $700{ }^{\circ} \mathrm{C}$. The mesopore volumes of the charcoal produced at 500 and $600{ }^{\circ} \mathrm{C}$ were similar, while the charcoal at $700{ }^{\circ} \mathrm{C}$ contained a much lower mesopore volume. Pore-size distribution does not show a clear correlation between temperature and reactivity.
According to the ultimate analysis (Table 2), the carbon to oxygen ratio increased from 8.9 to 16.8 and 26.3 when the pyrolysis temperature increased from 500 to 600 and $700{ }^{\circ} \mathrm{C}$, respectively. This means that an increase in pyrolysis temperature reduced the oxygenated functional groups on charcoal surfaces, meaning a smaller fraction of the active surface to react with $\mathrm{CO}_{2}$. In terms of the carbon structure, Figure 3a shows the Raman spectra of the charcoals at various temperatures. The position of the $\mathrm{D}$ band shifts toward a lower wavenumber when the temperature increased, while the position of the $\mathrm{G}$ band remains constant, which is associated with the formation of larger aromatic ring clusters. ${ }^{71}$ From the quantitative results shown in Figure $3 b, I_{D} / I_{G}$ ratios increased and $\mathrm{FWHM}_{\mathrm{D}}$ decreased when the temperature increased. This result indicates increased structural order and larger aromatic ring clusters at higher pyrolysis temperatures. This observation explains the continuous growth of aromatic ring clusters.

The total inorganic concentration of produced charcoal (Table S3) increased from 9071 to 9506 and $10,097 \mathrm{mg} \mathrm{kg}^{-1}$ when pyrolysis temperature increased from 500 to 600 and 700 ${ }^{\circ} \mathrm{C}$, respectively. During the pyrolysis, carbon and inorganic elements were enriched in charcoal. The results imply that most of the inorganic elements barely released during the isothermal pyrolysis, as indicated in previous work. ${ }^{51}$ Figure 4 depicts the concentration of the main elements, that is, $\mathrm{Ca}, \mathrm{K}$, $\mathrm{Mg}$, and $\mathrm{Si}$, in the charcoals. With increasing the pyrolysis temperature from 500 to $700{ }^{\circ} \mathrm{C}, \mathrm{Mg}, \mathrm{Ca}$, and $\mathrm{Si}$ concentrations did not show a significant trend. A higher absolute concentration of $\mathrm{K}$ was detected from charcoal produced at higher temperatures. The sudden increase in $\mathrm{K}$ concentration in the charcoal produced at a pyrolysis temperature of $700{ }^{\circ} \mathrm{C}$ may be the cause of the slightly higher reactivity in comparison with that produced at $600{ }^{\circ} \mathrm{C}$.

3.2.2. Heating Rate. In order to study the effect of heating rate, charcoal samples were produced at two distinct heating histories, namely, rapid heating under isothermal heating conditions $\left(\sim 175{ }^{\circ} \mathrm{C} \mathrm{min}^{-1}\right.$, estimated by particle simulation as shown in the Supporting Information, Figure S7) and a slow heating rate of $3{ }^{\circ} \mathrm{C} \mathrm{min}^{-1}$. Figure 5 shows the effect of heating rate on the gasification rate constants of the studied charcoals. The charcoals from slow pyrolysis have significantly lower rate constants compared to those produced under isothermal pyrolysis.

Previous studies on biomass powders ${ }^{29}$ found that a high surface area could partially explain the high reactivity of high heating rate charcoal. However, Table S4 shows that using large wood particles, charcoals produced from slow pyrolysis had a significantly higher surface area than charcoal produced from isothermal pyrolysis experiments. Under slow heating, the biomass gently releases volatiles through its pores, and the charcoal retains the vascular structure from the original biomass. On the other hand, under isothermal pyrolysis, the release of volatiles from internal to external particles is more intensive and rapid. It causes elevated local gas concentration and pressure inside the particles, yielding charcoal with larger cavities/openings and a more porous structure. Figure 6 shows the pore-size distribution of the charcoals. Charcoals from slow pyrolysis have a much higher micropore volume compared to those obtained from isothermal pyrolysis (Figure 6a). For the meso- and macropores shown in Figure $6 \mathrm{~b}$, the charcoals from slow pyrolysis contain comparable or slightly larger volumes, except for the pyrolysis under $\mathrm{CO}_{2}$. High meso- and macropore volumes of isothermal charcoals produced under 

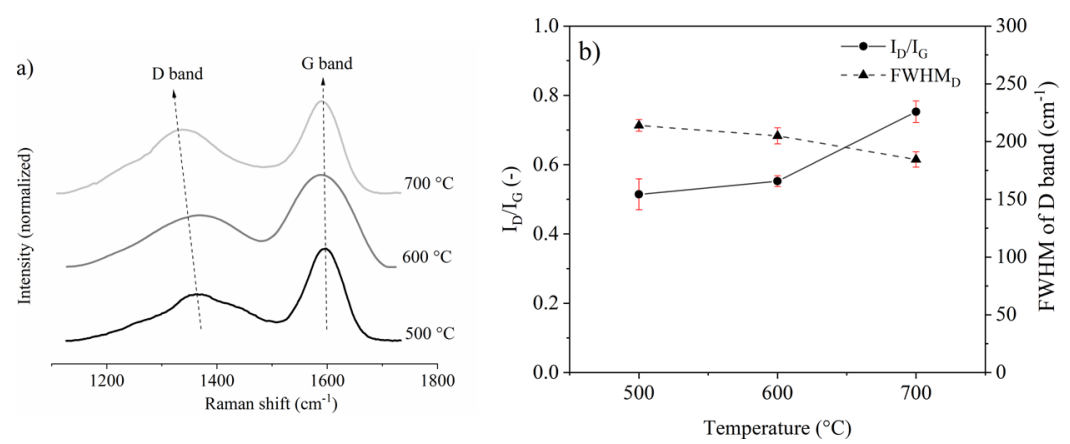

Figure 3. Raman analysis of the charcoals produced from isothermal pyrolysis at various temperatures; (a) Raman spectra; and (b) $I_{\mathrm{D}} / I_{\mathrm{G}}$ ratios and FWHM ${ }_{D}$ values. The error bars are the standard deviation obtained from five repetitions.

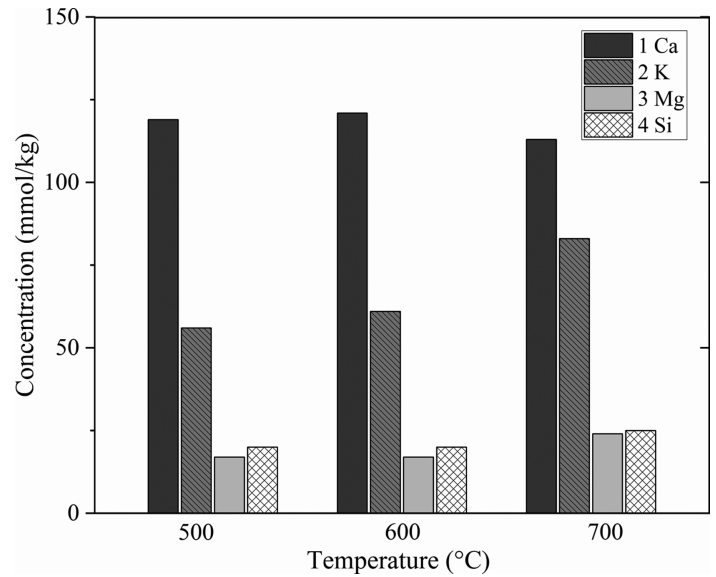

Figure 4. Absolute concentration of $\mathrm{Ca}, \mathrm{K}, \mathrm{Mg}$, and $\mathrm{Si}$ of the charcoals produced from isothermal pyrolysis at various temperatures.

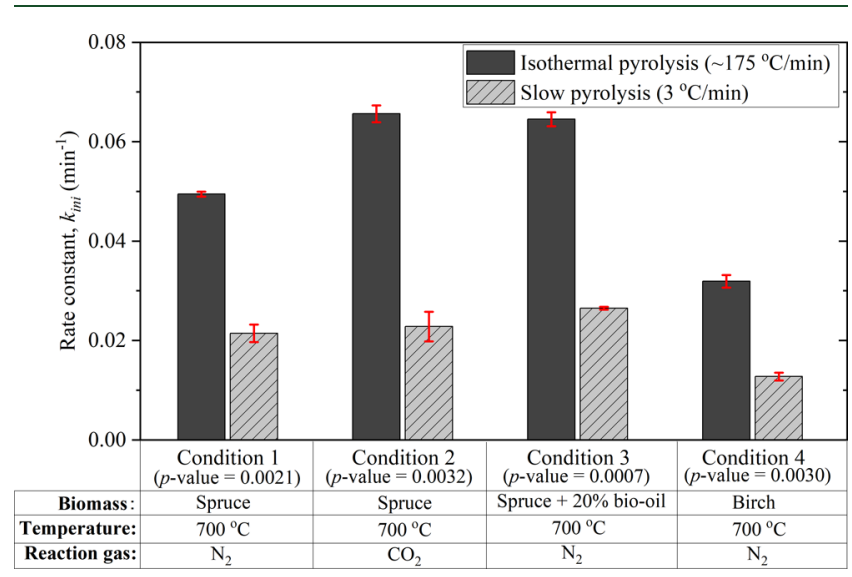

Figure 5. Comparison of rate constants of the charcoals obtained at the different heating rates. The error bars are the standard deviation obtained from two repetitions.

$\mathrm{CO}_{2}$ pyrolysis may be related to the increase in internal pressure because of low diffusivity, which will be discussed in a later section. According to the results of the pore-size distribution, charcoals from slow heating pyrolysis have a larger surface area but mostly contain inactive pores.

Under slow heating conditions, the pyrolysis reaction progresses with a low-temperature gradient inside the particle and the devolatilization time is longer than under isothermal pyrolysis conditions. Thus, slow heating charcoals tend to have a larger aromatic cluster size, which is commonly described as thermal annealing in the literature. ${ }^{32,35-37}$ The carbon content of slow pyrolysis charcoals is higher compared to those produced under isothermal pyrolysis, as shown in Table 2 . According to the results of the Raman spectroscopy, the $I_{\mathrm{D}} / I_{\mathrm{G}}$ ratios of the charcoals obtained from slow pyrolysis and isothermal pyrolysis do not show significant differences (Table 3). Nevertheless, the results of $\mathrm{FWHM}_{\mathrm{D}}$ depicted in Figure 7 show the difference between charcoals produced from experiments with different heating rates. The $\mathrm{FWHM}_{\mathrm{D}}$ of charcoals from slow pyrolysis was consistently lower than that of charcoals from isothermal pyrolysis. This result was confirmed by the X-ray diffraction (XRD) measurement of selected samples in the Supporting Information, Figure S8. The (002) and (100) XRD peaks become sharper in charcoal produced at a slow heating rate in comparison with isothermal pyrolysis, meaning there is a higher graphitized structure in the slow heating charcoal. These observations indicate that the charcoals from slow pyrolysis contain larger and more ordered structures of aromatic clusters compared to those obtained from isothermal pyrolysis.

Inorganic elements in charcoals can also play considerable roles in the gasification reaction of charcoal. Figure 8 shows a comparison of the total loss of inorganic elements calculated by

total loss of inorganic elements

$$
=\left(1-\frac{x_{\text {char }}^{\text {ash }}}{x_{\text {biomass }}^{\text {ash }}} y_{\text {char }}\right) \times 100 \%
$$

where $x_{\text {biomass }}^{\text {ash }}$ and $x_{\text {char }}^{\text {ash }}$ are total inorganic content of the biomass and charcoal, respectively, and $y_{\text {char }}$ is the mass yield of charcoal. The slow heating pyrolysis lost a higher amount of total inorganic elements compared to pyrolysis under isothermal conditions, except for the pyrolysis under $\mathrm{CO}_{2}$ (condition 2). This means that some inorganic elements are released to a higher degree during pyrolysis at the slow heating rate, which may be due to a long devolatilization time $(\sim 4 \mathrm{~h})$.

Figure 9 shows the comparison of $\mathrm{Ca}$ and $\mathrm{K}$ concentrations between charcoals from slow pyrolysis and isothermal pyrolysis. The concentrations of these elements were consistently lower in charcoals produced from slow pyrolysis, except for the pyrolysis under $\mathrm{CO}_{2}$ (condition 2). Using $\mathrm{CO}_{2}$ as a reaction gas in pyrolysis may increase the mass transfer resistance over solid particles, which lowers $\mathrm{K}$ release in slowheating pyrolysis. Another possible reason is that presence of $\mathrm{CO}_{2}$ may stabilize $\mathrm{K}$ and form carbonates during the pyrolysis. Without the effect of the reaction gas, however, the content of $\mathrm{Ca}$ and $\mathrm{K}$ is lower in the charcoals from slow pyrolysis compared to those obtained from isothermal pyrolysis. 

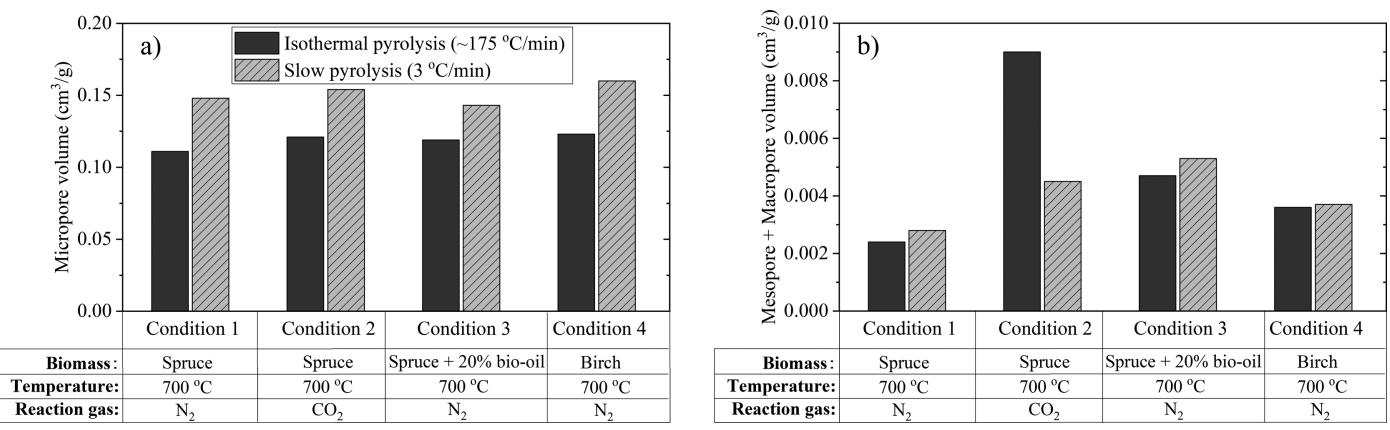

Figure 6. Comparison of micropore volume (a) and meso- and macropore volume (b) of the charcoals obtained at different heating rates.

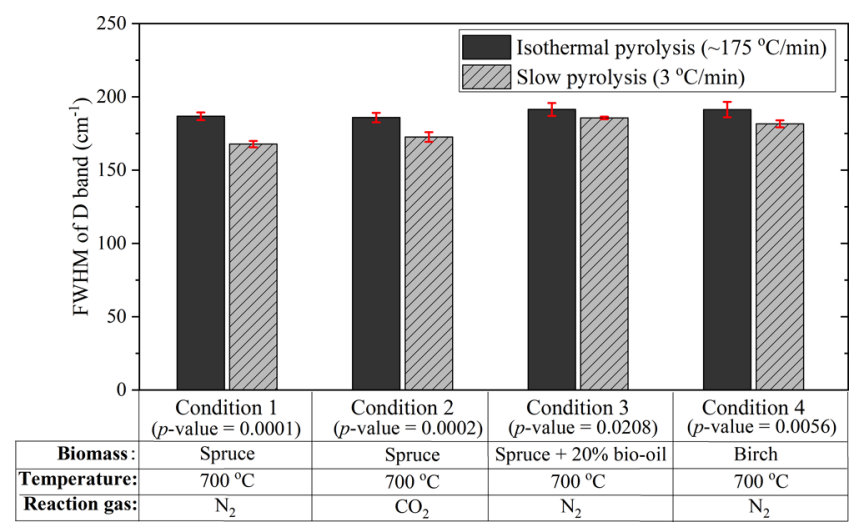

Figure 7. Comparison of $\mathrm{FWHM}_{\mathrm{D}}$ in the charcoals from different heating rates. The error bars are the standard deviation obtained from five repetitions.

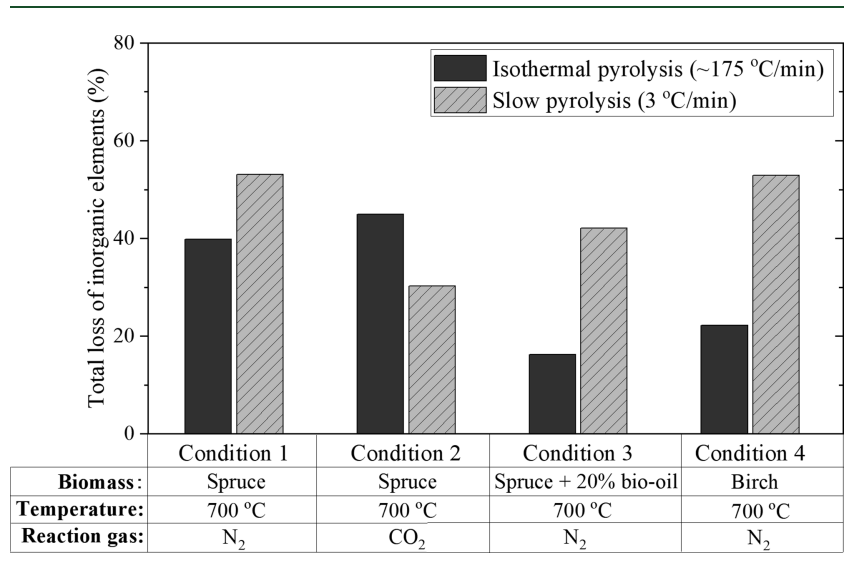

Figure 8. Total loss of inorganic elements of the charcoals produced at different heating rates.

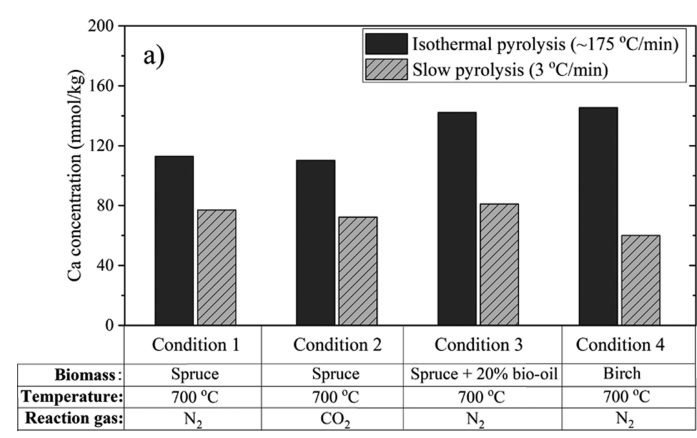

In summary, the charcoals from slow heating pyrolysis had a lower gasification reactivity compared to those produced from isothermal pyrolysis. The low reactivity can be due to a higher fraction of the inactive pore structure, stronger carbon structure, and lower $\mathrm{Ca}$ and $\mathrm{K}$ concentrations. All these results appear to be the consequence of longer pyrolysis time at the slow heating rate $(\sim 4 \mathrm{~h})$ than under the isothermal conditions $(\sim 15 \mathrm{~min})$. It is important to note that this effect may differ at different pyrolysis temperatures because the release of inorganic elements also depends on pyrolysis temperature.

3.2.3. Reaction Gas $\left(\mathrm{N}_{2}\right.$ vs $\left.\mathrm{CO}_{2}\right)$. Figure 10 shows the rate constants of charcoals produced under $\mathrm{N}_{2}$ and $\mathrm{CO}_{2}$ flows. In

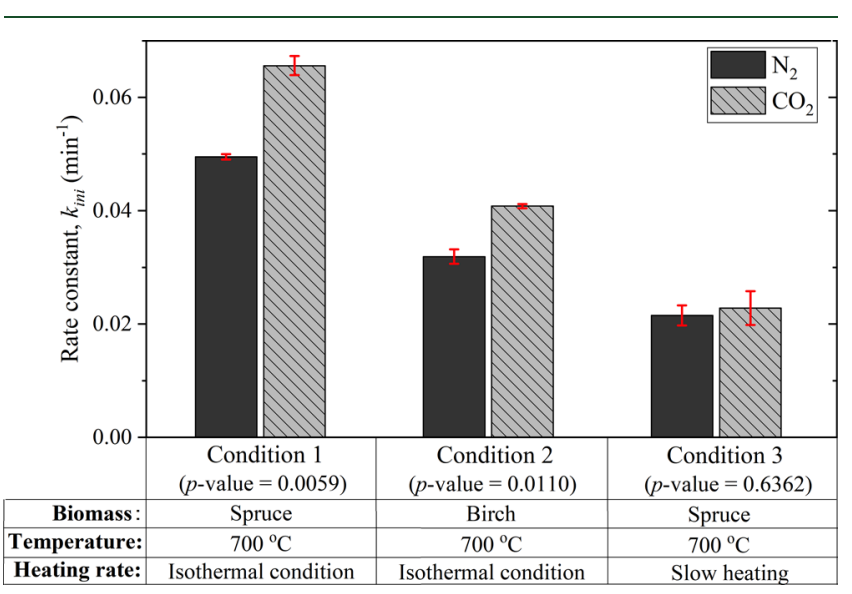

Figure 10. Rate constant of the charcoals produced from different reaction gases. The error bars are the standard deviation obtained from two repetitions.

the case of isothermal conditions (conditions 1 and 2), the rate constants of charcoals produced under a $\mathrm{CO}_{2}$ flow were significantly higher compared to those of charcoals produced

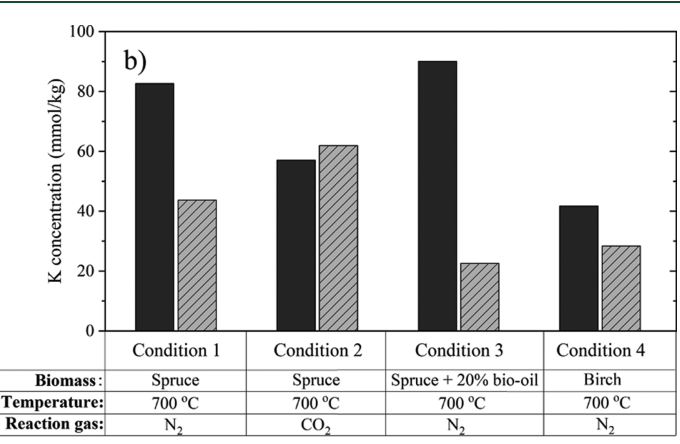

Figure 9. Concentration of $\mathrm{Ca}(\mathrm{a})$ and $\mathrm{K}(\mathrm{b})$ in the charcoals obtained at different heating rates. 

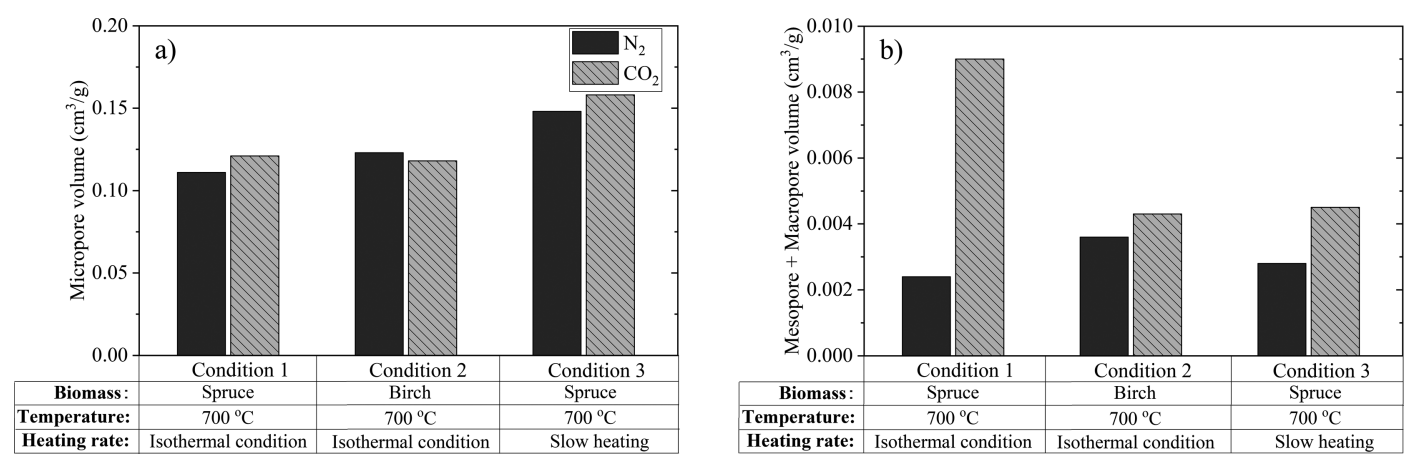

Figure 11. Comparison of micropore volume (a) and meso- and macropore volume (b) of the charcoals from different reaction gases.

under $\mathrm{N}_{2}$ flow. However, there was no significant difference in the case of slow pyrolysis (condition 3 ). These reactivity results are in contrast to the results of charcoals produced from wood powder. ${ }^{72,73}$

Figure 11 shows the specific pore volumes of micropores, mesopores, and macropores. The specific micropore volume showed no consistent differences between the charcoals produced from $\mathrm{N}_{2}$ and $\mathrm{CO}_{2}$ pyrolysis (Figure 11a). According to Figure $11 \mathrm{~b}$, the mesopore and macropore volumes of the charcoals produced under $\mathrm{CO}_{2}$ flow were consistently higher compared to those produced under $\mathrm{N}_{2}$ flow. The differences of pore volumes obtained under $\mathrm{N}_{2}$ and $\mathrm{CO}_{2}$ flows were most likely caused by a difference in the diffusivity of volatiles in the two different atmospheres, as discussed in the previous work. ${ }^{7}$ A lower diffusivity of volatiles under $\mathrm{CO}_{2}$ pyrolysis can result in higher internal pressure and cause the pore structure to rupture, that is, form more mesopores and macropores. This behavior does not appear during the pyrolysis of wood powder because the particle size is too small to develop high internal pressure. Thus, high specific mesopore and macropore volumes in the charcoals from $\mathrm{CO}_{2}$ pyrolysis could be the specific result of large particles only. It could explain the contradictory effects of the reaction gas during pyrolysis between this study (woodchips) and the literature (wood powders) ${ }^{72,73}$ Nevertheless, in the case of pyrolysis at a slow heating rate (condition 3 ), the high mesopore and macropore volume of the charcoal from $\mathrm{CO}_{2}$ pyrolysis did not result in a significant difference in the rate constant, probably because of other counteracting effects.

The ultimate analysis (Table 2) and inorganic content (Table S3) showed no consistent difference between the charcoals obtained from experiments using the two reaction gases. The FWHM of the D band shows no significant difference between the two reaction gases for conditions 1 and 2 , according to Table 3 . On the contrary, for slow heating rate experiments under condition 3 , the charcoal produced in the presence of $\mathrm{CO}_{2}$ has a higher $\mathrm{FWHM}_{\mathrm{D}}$ value than $\mathrm{N}_{2}$ pyrolysis charcoal (with a $p$-value of 0.0245 ). This means that the $\mathrm{D}$ band of charcoal from $\mathrm{CO}_{2}$ pyrolysis is broader compared to that from $\mathrm{N}_{2}$ pyrolysis. These results imply that charcoal produced from $\mathrm{CO}_{2}$ pyrolysis has smaller aromatic clusters at a slow heating rate. On the other hand, there are no significant differences in $\mathrm{FWHM}_{\mathrm{D}}$ values of charcoal pyrolyzed under isothermal conditions. Nevertheless, these results still cannot give a clear explanation of the similar reactivity level between charcoals from $\mathrm{N}_{2}$ and $\mathrm{CO}_{2}$ pyrolysis at a slow heating rate.

3.2.4. Raw Materials. The charcoals studied in this work were prepared from different wood species, namely spruce (softwood) and birch (hardwood). The fiber structures of these woods are different and contain different organic and inorganic compositions. ${ }^{7}$ Figure 12 shows the rate constants of

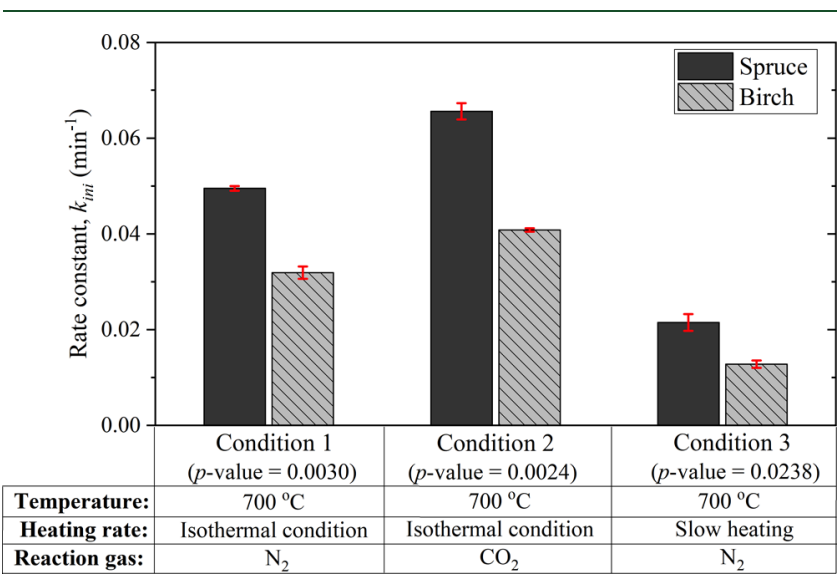

Figure 12. Rate constant of the charcoals produced from different biomass species. The error bars are the standard deviation obtained from two repetitions.

the charcoals produced from spruce and birch under various conditions. The rate constants of spruce charcoals were significantly higher (i.e., more reactive charcoal) than those of birch charcoals.

Spruce charcoals and birch charcoals contain an equivalent level of specific pore volume (see Table S4 in the Supporting Information). However, spruce charcoals have a slightly higher macropore volume compared to birch charcoals. The carbon structure of the charcoals shows that spruce charcoals have a slightly larger and highly ordered structure of aromatic clusters (Table 3). Thus, neither the morphological structure nor carbon structure is likely to be the primary explanation of the difference in the charcoal reactivity between these two samples.

The content of catalytically active inorganic species could explain the different reactivities of the charcoals produced from different wood species. Figure 13 shows the concentration of $\mathrm{Ca}$ and $\mathrm{K}$ in the charcoals produced from spruce and birch. The $\mathrm{Ca}$ concentration showed no consistent differences between spruce charcoals and birch charcoals, while the $\mathrm{K}$ concentrations of spruce charcoals are higher compared to those of birch charcoals. This analysis result corresponds to a higher amount of $\mathrm{K}$ and $\mathrm{Ca}$ in raw spruce compared to raw birch (see Table $\mathrm{S} 1$ in the Supporting Information). K generally plays a more significant role than $\mathrm{Ca}$ in the gasification of charcoal by promoting certain reactions. According to a thermodynamic equilibrium calculation conducted in previous work, ${ }^{18} \mathrm{~K}$ tends to be released at a 

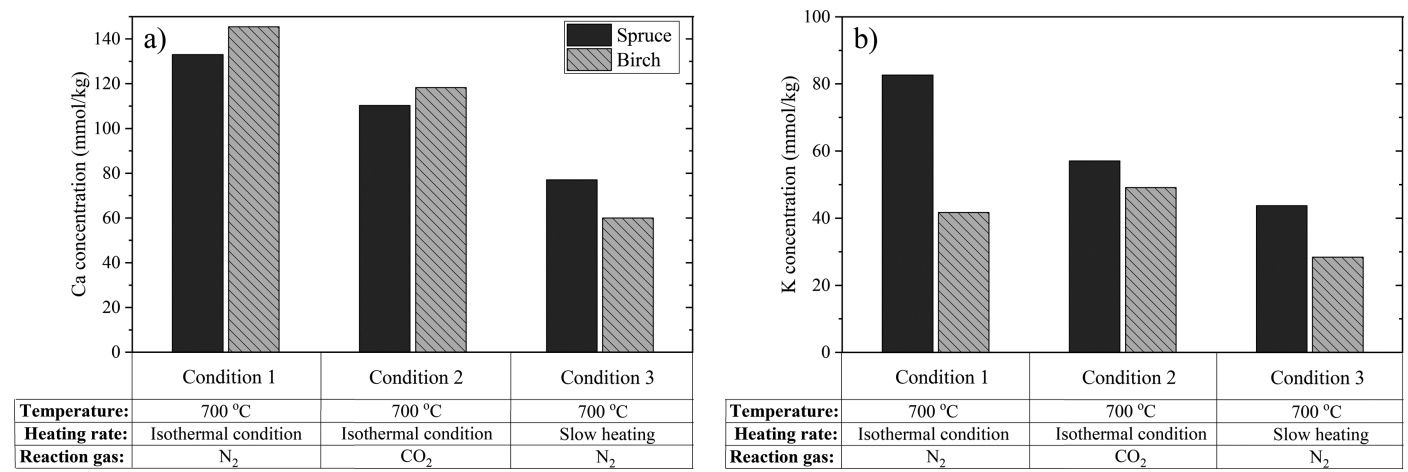

Figure 13. Concentration of $\mathrm{Ca}(\mathrm{a})$ and $\mathrm{K}(\mathrm{b})$ in the charcoals produced from different biomass species.

temperature higher than $800{ }^{\circ} \mathrm{C}$ under oxidizing conditions, while $\mathrm{Ca}$ remains in the solid phase. The release of $\mathrm{K}$ implies the mobility of $\mathrm{K}$ throughout the charcoal particles, resulting in a catalytic effect during the gasification reaction. Hence, the higher amount of $\mathrm{K}$ in spruce charcoals could explain the slightly higher reactivity compared to birch charcoals.

Besides wood species, the effects of bio-oil embedding were studied. Figure 14 shows the rate constants of the charcoals

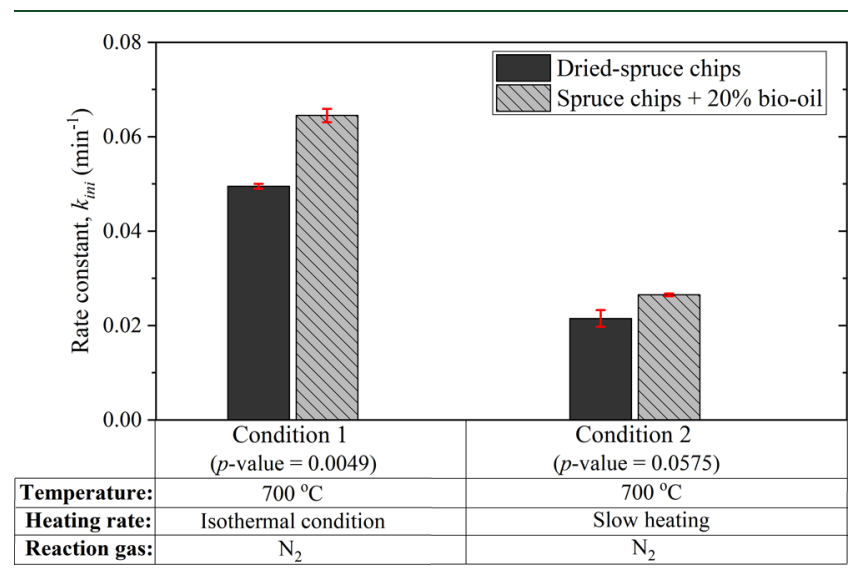

Figure 14. Rate constant in the comparison between the charcoals from bio-oil-embedded woodchips and dried woodchips. The error bars are the standard deviation obtained from two repetitions.

obtained from dried spruce and bio-oil-embedded spruce under conditions 1 and 2 . The charcoals obtained from bio-oilembedded spruce showed significantly higher reactivity compared to those obtained from dried spruce. The result also shows a higher impact of bio-oil recycling on charcoal reactivity when the technique is applied to pyrolysis under isothermal conditions compared to slow heating pyrolysis.

Figure 15 shows the pore-size distribution of the charcoals produced from dried spruce and bio-oil-embedded spruce in conditions 1 and 2 . The micropores are at the equivalent level (Figure 15a), while the mesopores and macropores increased when the bio-oil embedding technique was applied (Figure $15 \mathrm{~b})$. The embedding of bio-oil to woodchips reduced the diffusivity of volatiles during pyrolysis, leading to overpressure and rupture of the pore structure, creating a high degree of mesopores and macropores. More mesopores and macropores in the charcoals obtained from bio-oil-embedded spruce could explain their slightly higher reactivity compared to those produced from dried spruce.

Figure 16 shows the $\mathrm{FWHM}_{\mathrm{D}}$ of the charcoals produced from dried spruce and bio-oil-embedded spruce in conditions 1 and 2. The $\mathrm{FWHM}_{\mathrm{D}}$ of the charcoals produced from bio-oilembedded spruce is slightly wider than that of the charcoals produced from dried spruce. Although the differences in the $\mathrm{FWHM}_{\mathrm{D}}$ were not significant for condition 1, the charcoals from bio-oil-embedded spruce had a lower carbon content compared to those obtained from dried spruce (see Table 2). This means that the charcoals from bio-oil-embedded spruce contain less-developed structures of aromatic clusters compared to those obtained from dried spruce, resulting in them being more reactive during the gasification reaction.

According to the inorganic element composition (Table S3), no consistent correlation can be observed between inorganic element levels and the effect of bio-oil embedding. In conclusion, the increase in charcoal reactivity by embedding bio-oil on woodchips can be explained by the increase in the
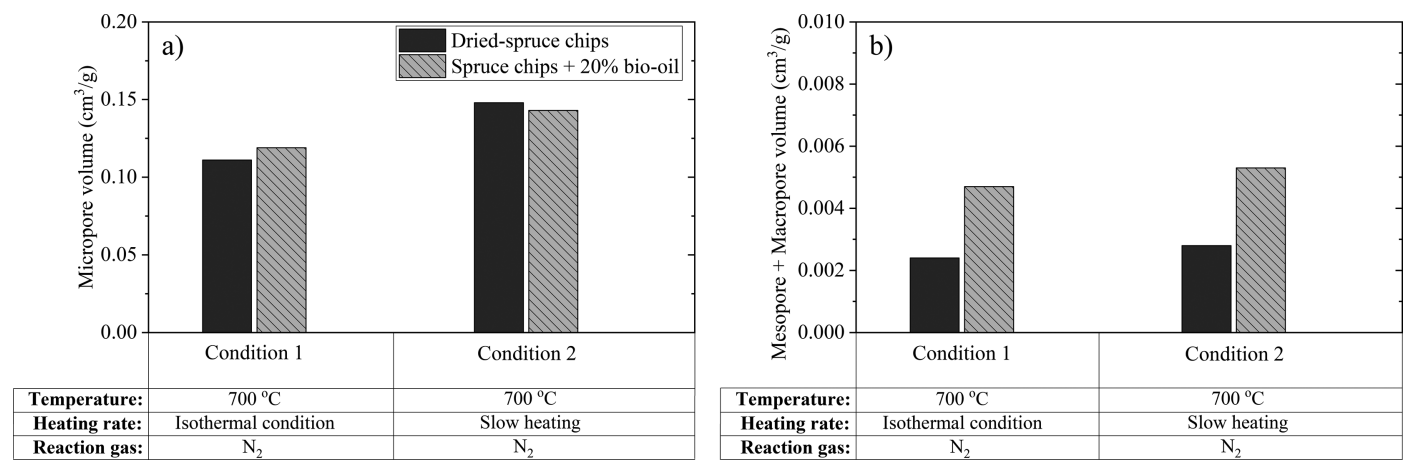

Figure 15. Comparison of micropore volume (a) and meso- and macropore volume (b) of the charcoals from woodchips with and without bio-oil embedding. 


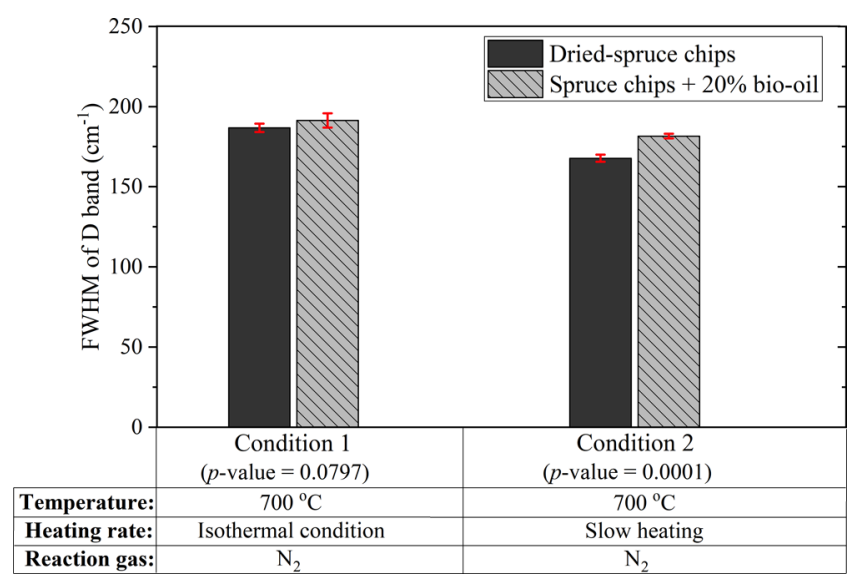

Figure 16. Comparison of $\mathrm{FWHM}_{\mathrm{D}}$ in the charcoals from bio-oilembedded woodchips and dried woodchips. The error bars are the standard deviation obtained from five repetitions.

combination of specific meso- and macropore volumes and a disordered aromatic structure.

\section{CONCLUSIONS}

This study investigated the effects of pyrolysis conditions on gasification reactivity and the properties of charcoals from large particles, that is, woodchips. The difference in the physical structure of charcoal, such as the meso- and macropore volume and the size and carbon structure order of aromatic clusters, is the main reason for the reactivity differences. The charcoal produced under slow pyrolysis conditions has a low amount of mesopores and macropores and larger and well-ordered aromatic clusters, which are characterized by a low gasification reactivity. On the other hand, for the charcoals with a similar physical structure and chemical properties, inorganic elements, particularly $\mathrm{Ca}$ and $\mathrm{K}$ in charcoal, play more significant roles in affecting their gasification reactivity.

The pyrolysis heating rate and temperature significantly impacted the properties and reactivity of the charcoals, while other parameters, that is, pyrolysis gas atmosphere, type of wood species, and bio-oil embedding, had a less significant impact by a comparative factor of ca. 0.5 or below. The charcoal produced from the slow heating rate had lower reactivity partially because of a more stable chemical structure and lower amounts of catalytically active elements. Unlike the pyrolysis of wood powder, the total specific surface area had no clear correlation with gasification reactivity at different heating rates. A higher release degree of total inorganic elements was observed in pyrolysis under slow heating rate to the pyrolysis temperature of $700{ }^{\circ} \mathrm{C}$ because of a relatively long devolatilization time $(\sim 4 \mathrm{~h})$. Meanwhile, the increase in pyrolysis temperature led to less-reactive charcoal because of a higher degree of devolatilization, loss of functional groups, and the growth of aromatic ring clusters. For low-Si feedstocks such as the charcoals in this work, the catalytic role of $\mathrm{K}$ is more pronounced than that of $\mathrm{Ca}$ for the specific gasification conditions applied in this work. Thus, the higher reactivity of spruce charcoals compared to birch charcoals was explained by a higher $\mathrm{K}$ concentration in the raw biomass.

The promotion of secondary char formation suggested in our previous study, ${ }^{7}$ that is, by bio-oil embedding and purging with $\mathrm{CO}_{2}$, was found to slightly increase the gasification reactivity of charcoal. Bio-oil embedding on woodchips led to the production of charcoals from various sources, that is, woodchips, bio-oil, and the interaction between woodchips and bio-oil. Charcoal from bio-oil and secondary char formation contained smaller aromatic structures compared to primary charcoal from pure woodchips. Embedding bio-oil on woodchips also led to an increasing meso- and macropore volume in the charcoal because of high internal pressure and rupture of the pore structure. The same outcome was observed when using $\mathrm{CO}_{2}$ as a reaction gas during pyrolysis instead of $\mathrm{N}_{2}$ because of the lower diffusivity of volatiles in $\mathrm{CO}_{2}$ pyrolysis. The change in the porous structure resulting from high internal pressure only appears in the pyrolysis of large particles and cannot be observed in the pyrolysis of pulverized biomass. Additionally, charcoal produced under $\mathrm{CO}_{2}$ pyrolysis at a low heating rate contains smaller aromatic clusters than that by $\mathrm{N}_{2}$ pyrolysis under the same conditions.

The findings from this work could be further implemented in the development of an efficient tailor-made charcoal production process for a specific industrial process. Our previous study ${ }^{7}$ proposed conditions, that is, pyrolysis of a thick particle under slow pyrolysis with bio-oil recycling and $\mathrm{CO}_{2}$ purging, which increase the carbon yield by a factor of ca. 1.7. Although bio-oil recycling and $\mathrm{CO}_{2}$ purging were found to increase the reactivity of charcoal, a more dramatic decrease in reactivity was achieved using a slow heating rate compared to a fast heating rate. Thus, the reactivity of charcoal produced under different conditions can be significantly different and it is possible to tailor the reactivity toward the need (low or high reactivity) of specific industrial processes by controlling charcoal production conditions and feedstock properties.

\section{ASSOCIATED CONTENT}

\section{SI Supporting Information}

The Supporting Information is available free of charge at https://pubs.acs.org/doi/10.1021/acs.energyfuels.0c00592.

Preparation of charcoal, characteristics of the woodchips and bio-oil used in this study, pyrolysis of raw materials, inorganic compositions of charcoals, porous structure of charcoals, treatment of reactivity data from the TGA experiment, examples of data fitting using the random pore model, adsorption isotherms, deconvolution of Raman spectra, $\mathrm{K}-\mathrm{Ca}-\mathrm{Si}$ ternary diagram for the charcoals, estimation of heating rate in isothermal pyrolysis, and XRD diffraction patterns (PDF)

\section{AUTHOR INFORMATION}

\section{Corresponding Author}

Aekjuthon Phounglamcheik - Division of Energy Science, Luleå University of Technology, 97187 Luleå, Sweden; ○ orcid.org/0000-0001-8372-4386; Phone: +46 92049 3939; Email: aekjuthon.phounglamcheik@ltu.se, aekjuthonp@gmail.com

\section{Authors}

Liang Wang - SINTEF Energy Research, 7465 Trondheim, Norway; orcid.org/0000-0002-1458-7653

Henrik Romar - Research Unit of Sustainable Chemistry, Oulu University, 900140 Oulu, Finland

Norbert Kienzl - BEST-Bioenergy and Sustainable Technologies GmbH, 8010 Graz, Austria 
Markus Broström - Department of Applied Physics and Electronics, Umeå University, 90187 Umeå, Sweden; (1) orcid.org/0000-0003-1095-9154

Kerstin Ramser - Division of Fluid and Experimental Mechanics, Luleå University of Technology, 97187 Luleå, Sweden

Øyvind Skreiberg - SINTEF Energy Research, 7465 Trondheim, Norway

Kentaro Umeki - Division of Energy Science, Luleå University of Technology, 97187 Luleå, Sweden; 이이.org/00000001-6081-5736

Complete contact information is available at: https://pubs.acs.org/10.1021/acs.energyfuels.0c00592

\section{Author Contributions}

The manuscript was written through the contributions of all authors. All authors have given approval to the final version of the manuscript.

\section{Notes}

The authors declare no competing financial interest.

\section{ACKNOWLEDGMENTS}

The authors acknowledge the financial support of Interreg Nord and Norrbotten County Board through the RENEPRO project (20200224), European Regional Development Fund, Region Norrbotten, and Region Västerbotten through the Bio4Metal project (20200585), Swedish National Strategic Research Environment, Bio4Energy, Swedish Centre for Biomass Gasification, the Kempe Foundation, and the Swedish Energy Agency (P46974-1). The Norwegian authors acknowledge the financial support from the BioCarbUp project, which is funded by the Research Council of Norway and industrial partners. In addition, the authors would like to offer their special thanks to Dr. Albert Bach-Oller and Ali Hedayati for discussion on the catalytic activity of inorganic species.

\section{REFERENCES}

(1) Dai, J.; Sokhansanj, S.; Grace, J. R.; Bi, X.; Lim, C. J.; Melin, S. Overview and some issues related to co-firing biomass and coal. Can. J. Chem. Eng. 2008, 86, 367-386.

(2) Blackwood Technology. Co-Firing of Biomass. Blackwood Technol 2017. http://www.blackwood-technology.com/applications/ co-firing/ (accessed November 7, 2018).

(3) Molino, A.; Larocca, V.; Chianese, S.; Musmarra, D. Biofuels production by biomass gasification: A review. Energies 2018, 11, 811831.

(4) Suopajärvi, H.; Umeki, K.; Mousa, E.; Hedayati, A.; Romar, H.; Kemppainen, A.; et al. Use of biomass in integrated steelmaking Status quo, future needs and comparison to other low-CO2steel production technologies. Appl. Energy 2018, 213, 384-407.

(5) Mousa, E.; Wang, C.; Riesbeck, J.; Larsson, M. Biomass applications in iron and steel industry: An overview of challenges and opportunities. Renewable Sustainable Energy Rev. 2016, 65, 12471266.

(6) Wang, C.; Mellin, P.; Lövgren, J.; Nilsson, L.; Yang, W.; Salman, $\mathrm{H}$.; et al. Biomass as blast furnace injectant - Considering availability, pretreatment and deployment in the Swedish steel industry. Energy Convers. Manage. 2015, 102, 217-226.

(7) Phounglamcheik, A.; Wretborn, T.; Umeki, K. Increasing efficiency of charcoal production with bio-oil recycling. Energy Fuels 2018, 32, 9650-9658.

(8) Farrokh, N. T.; Suopajärvi, H.; Mattila, O.; Umeki, K.; Phounglamcheik, A.; Romar, H.; et al. Slow pyrolysis of by-product lignin from wood-based ethanol production- A detailed analysis of the produced chars. Energy 2018, 164, 112-123.
(9) Di Blasi, C. Combustion and gasification rates of lignocellulosic chars. Prog. Energy Combust. Sci. 2009, 35, 121-140.

(10) Bouraoui, Z.; Jeguirim, M.; Guizani, C.; Limousy, L.; Dupont, C.; Gadiou, R. Thermogravimetric study on the influence of structural, textural and chemical properties of biomass chars on CO2 gasification reactivity. Energy 2015, 88, 703-710.

(11) Laurendeau, N. M. Heterogeneous kinetics of coal char gasification and combustion. Prog. Energy Combust. Sci. 1978, 4, 221270

(12) Mermoud, F.; Salvador, S.; Vandesteene, L.; Golfier, F. Influence of the pyrolysis heating rate on the steam gasification rate of large wood char particles. Fuel 2006, 85, 1473-1482.

(13) Asadullah, M.; Zhang, S.; Min, Z.; Yimsiri, P.; Li, C.-Z. Effects of biomass char structure on its gasification reactivity. Bioresour. Technol. 2010, 101, 7935-7943.

(14) Raveendran, K.; Ganesh, A. Adsorption characteristics and pore-development of biomass-pyrolysis char. Fuel 1998, 77, 769-781.

(15) Zolin, A.; Jensen, A.; Jensen, P. A.; Frandsen, F.; DamJohansen, $\mathrm{K}$. The influence of inorganic materials on the thermal deactivation of fuel chars. Energy Fuels 2001, 15, 1110.

(16) Encinar, J. M.; González, J. F.; Rodríguez, J. J.; Ramiro, M. J. Catalysed and uncatalysed steam gasification of eucalyptus char: Influence of variables and kinetic study. Fuel 2001, 80, 2025-2036.

(17) Kannan, M. P.; Richards, G. N. Gasification of biomass chars in carbon dioxide: dependence of gasification rate on the indigenous metal content. Fuel 1990, 69, 747-753.

(18) Strandberg, A.; Carlborg, M.; Boman, C.; Broström, M. Ash Transformation During Single-Pellet Combustion of a Silicon-Poor Woody Biomass. Energy Fuels 2019, 33, 7770.

(19) McKee, D. W. Gasification of graphite in carbon dioxide and water vapor-the catalytic effects of alkali metal salts. Carbon 1982, 20, 59.

(20) Nzihou, A.; Stanmore, B.; Sharrock, P. A review of catalysts for the gasification of biomass char, with some reference to coal. Energy 2013, 58, 305.

(21) Boström, D.; Skoglund, N.; Grimm, A.; Boman, C.; Öhman, M.; Broström, M.; et al. Ash transformation chemistry during combustion of biomass. Energy Fuels 2012, 26, 85.

(22) Wang, L.; Skreiberg, Ø.; Gronli, M.; Specht, G. P.; Antal, M. J. Is elevated pressure required to achieve a high fixed-carbon yield of charcoal from biomass? Part 2: The importance of particle size. Energy Fuels 2013, 27, 2146.

(23) Monti, A.; Di Virgilio, N.; Venturi, G. Mineral composition and ash content of six major energy crops. Biomass Bioenergy 2008, 32, 216.

(24) Werkelin, J.; Skrifvars, B.-J.; Hupa, M. Ash-forming elements in four Scandinavian wood species. Part 1: Summer harvest. Biomass Bioenergy 2005, 29, 451.

(25) Lindström, E.; Öhman, M.; Backman, R.; Boström, D. Influence of sand contamination on slag formation during combustion of wood derived fuels. Energy Fuels 2008, 22, 2216.

(26) Barta-Rajnai, E.; Wang, L.; Sebestyén, Z.; Barta, Z.; Khalil, R.; Skreiberg, $\varnothing$; i et al. Comparative study on the thermal behavior of untreated and various torrefied bark, stem wood, and stump of Norway spruce. Appl. Energy 2017, 204, 1043.

(27) DeGroot, W. F.; Shafizadeh, F. Kinetics of gasification of Douglas Fir and Cottonwood chars by carbon dioxide. Fuel 1984, 63, 210.

(28) Roberts, D. G.; Harris, D. J.; Wall, T. F. On the Effects of High Pressure and Heating Rate during Coal Pyrolysis on Char Gasification Reactivity. Energy Fuels 2003, 17, 887-895.

(29) Cetin, E.; Moghtaderi, B.; Gupta, R.; Wall, T. F. Influence of pyrolysis conditions on the structure and gasification reactivity of biomass chars. Fuel 2004, 83, 2139-2150.

(30) Septien, S.; Escudero Sanz, F. J.; Salvador, S.; Valin, S. The effect of pyrolysis heating rate on the steam gasification reactivity of char from woodchips. Energy 2018, 142, 68.

(31) Zeng, K.; Minh, D. P.; Gauthier, D.; Weiss-Hortala, E.; Nzihou, A.; Flamant, G. The effect of temperature and heating rate on char 
properties obtained from solar pyrolysis of beech wood. Bioresour. Technol. 2015, 182, 114.

(32) Guerrero, M.; Ruiz, M. P.; Alzueta, M. U.; Bilbao, R.; Millera, A. Pyrolysis of eucalyptus at different heating rates: Studies of char characterization and oxidative reactivity. J. Anal. Appl. Pyrolysis 2005, 74, 307-314.

(33) Morin, M.; Pécate, S.; Hémati, M.; Kara, Y. Pyrolysis of biomass in a batch fluidized bed reactor: Effect of the pyrolysis conditions and the nature of the biomass on the physicochemical properties and the reactivity of char. J. Anal. Appl. Pyrolysis 2016, 122, 511-523.

(34) Guerrero, M.; Ruiz, M. P.; Millera, Á.; Alzueta, M. U.; Bilbao, R. Characterization of biomass chars formed under different devolatilization conditions: Differences between rice husk and Eucalyptus. Energy Fuels 2008, 22, 1275.

(35) Della Rocca, P. A.; Cerrella, E. G.; Bonelli, P. R.; Cukierman, A. L. Pyrolysis of hardwoods residues: On kinetics and chars characterization. Biomass Bioenergy 1999, 16, 79-88.

(36) Kurosaki, F.; Ishimaru, K.; Hata, T.; Bronsveld, P.; Kobayashi, E.; Imamura, Y. Microstructure of wood charcoal prepared by flash heating. Carbon 2003, 41, 3057-3062.

(37) Fushimi, C.; Araki, K.; Yamaguchi, Y.; Tsutsumi, A. Effect of heating rate on steam gasification of biomass. 1. Reactivity of char. Ind. Eng. Chem. Res. 2003, 42, 3922-3928.

(38) Brown, R. A.; Kercher, A. K.; Nguyen, T. H.; Nagle, D. C.; Ball, W. P. Production and characterization of synthetic wood chars for use as surrogates for natural sorbents. Org. Geochem. 2006, 37, 321-333.

(39) Keiluweit, M.; Nico, P. S.; Johnson, M. G.; Kleber, M. Dynamic molecular structure of plant biomass-derived black carbon (biochar). Environ. Sci. Technol. 2010, 44, 1247-1253.

(40) Antal, M. J.; Grønli, M. The Art, Science, and Technology of Charcoal Production. Ind. Eng. Chem. Res. 2003, 42, 1619-1640.

(41) Noumi, E. S.; Blin, J.; Valette, J.; Rousset, P. Combined Effect of Pyrolysis Pressure and Temperature on the Yield and $\mathrm{CO} 2$ Gasification Reactivity of Acacia Wood in macro-TG. Energy Fuels 2015, 29, 7301-7308.

(42) Smith, M. W.; Dallmeyer, I.; Johnson, T. J.; Brauer, C. S.; McEwen, J.-S.; Espinal, J. F.; et al. Structural analysis of char by Raman spectroscopy: Improving band assignments through computational calculations from first principles. Carbon 2016, 100, 678-692.

(43) Robertson, J. Diamond-like amorphous carbon. Mater. Sci. Eng., R 2002, 37, 129-281.

(44) Asadullah, M.; Zhang, S.; Li, C.-Z. Evaluation of structural features of chars from pyrolysis of biomass of different particle sizes. Fuel Process. Technol. 2010, 91, 877-881.

(45) Sharma, R. K.; Wooten, J. B.; Baliga, V. L.; Hajaligol, M. R. Characterization of chars from biomass-derived materials: Pectin chars. Fuel 2001, 80, 1825-1836.

(46) Sharma, R. K.; Wooten, J. B.; Baliga, V. L.; Lin, X.; Geoffrey Chan, W.; Hajaligol, M. R. Characterization of chars from pyrolysis of lignin. Fuel 2004, 83, 1469-1482.

(47) Olsson, J. G.; Jäglid, U.; Pettersson, J. B. C.; Hald, P. Alkali metal emission during pyrolysis of biomass. Energy Fuels 1997, 11, $779-784$.

(48) Jensen, P. A.; Frandsen, F. J.; Dam-Johansen, K.; Sander, B. Experimental Investigation of the Transformation and Release to Gas Phase of Potassium and Chlorine during Straw Pyrolysis. Energy Fuels 2000, 14, 1280-1285.

(49) Davidsson, K. O.; Stojkova, B. J.; Pettersson, J. B. C. Alkali emission from birchwood particles during rapid pyrolysis. Energy Fuels 2002, 16, 1033-1039.

(50) Okuno, T.; Sonoyama, N.; Hayashi, J.-i.; Li, C.-Z.; Sathe, C.; Chiba, T. Primary release of alkali and alkaline earth metallic species during the pyrolysis of pulverized biomass. Energy Fuels 2005, 19, 2164-2171.

(51) Anca-Couce, A.; Dieguez-Alonso, A.; Zobel, N.; Berger, A.; Kienzl, N.; Behrendt, F. Influence of Heterogeneous Secondary Reactions during Slow Pyrolysis on Char Oxidation Reactivity of Woody Biomass. Energy Fuels 2017, 31, 2335-2344.
(52) Lin, L.; Strand, M. Investigation of the intrinsic CO2gasification kinetics of biomass char at medium to high temperatures. Appl. Energy 2013, 109, 220-228.

(53) Brunauer, S.; Emmett, P. H.; Teller, E. Adsorption of Gases in Multimolecular Layers. J. Am. Chem. Soc. 1938, 60, 309-319.

(54) Barrett, E. P.; Joyner, L. G.; Halenda, P. P. The Determination of Pore Volume and Area Distributions in Porous Substances. I. Computations from Nitrogen Isotherms. J. Am. Chem. Soc. 1951, 73, $373-380$.

(55) Seaton, N. a.; Walton, J. P. R. B.; Quirke, N. A new analysis method for the determination of the pore size distribution of porous carbons from nitrogen adsorption measurements. Carbon 1989, 27, 853-861.

(56) Schulze, H. G.; Turner, R. F. B. A Two-Dimensionally coincident second difference cosmic ray spike removal method for the fully automated processing of raman spectra. Appl. Spectrosc. 2014, 68, 185-191.

(57) Savitzky, A.; Golay, M. J. E. Smoothing and Differentiation of Data by Simplified Least Squares Procedures. Anal. Chem. 1964, 36, $1627-1639$.

(58) Cao, A.; Pandya, A. K.; Serhatkulu, G. K.; Weber, R. E.; Dai, H.; Thakur, J. S.; et al. A robust method for automated background subtraction of tissue fluorescence. J. Raman Spectrosc. 2007, 38, 1199-1205.

(59) Li, X.; Hayashi, J.; Li, C. Volatilisation and catalytic effects of alkali and alkaline earth metallic species during the pyrolysis and gasification of Victorian brown coal. Part VII. Raman spectroscopic study on the changes in char structure during the catalytic gasification in air. Fuel 2006, 85, 1509-1517.

(60) Rhim, Y.-R.; Zhang, D.; Fairbrother, D. H.; Wepasnick, K. A.; Livi, K. J.; Bodnar, R. J.; et al. Changes in electrical and microstructural properties of microcrystalline cellulose as function of carbonization temperature. Carbon 2010, 48, 1012.

(61) Ishimaru, K.; Hata, T.; Bronsveld, P.; Nishizawa, T.; Imamura, Y. Characterization of sp2- and sp3-bonded carbon in wood charcoal. J. Wood Sci. 2007, 53, 442.

(62) Guizani, C.; Jeguirim, M.; Valin, S.; Limousy, L.; Salvador, S. Biomass chars: The effects of pyrolysis conditions on their morphology, structure, chemical properties and reactivity. Energies 2017, 10, 796.

(63) McDonald-Wharry, J.; Manley-Harris, M.; Pickering, K. Carbonisation of biomass-derived chars and the thermal reduction of a graphene oxide sample studied using Raman spectroscopy. Carbon 2013, 59, 383-405.

(64) Senneca, O.; Apicella, B.; Heuer, S.; Schiemann, M.; Scherer, V.; Stanzione, F.; et al. Effects of $\mathrm{CO} 2$ on submicronic carbon particulate (soot) formed during coal pyrolysis in a drop tube reactor. Combust. Flame 2016, 172, 302.

(65) O’Haver, T. peakfit.m version 9.0 2018. "http://se.mathworks. $\mathrm{com} /$ matlabcentral/fileexchange/23611-peakfit-m" (accessed May 8, 2019).

(66) Tuinstra, F.; Koenig, J. L. Raman Spectrum of Graphite. J. Chem. Phys. 1970, 53, 1126-1130.

(67) Bar-Ziv, E.; Zaida, A.; Salatino, P.; Senneca, O. Diagnostics of carbon gasification by Raman microprobe spectroscopy. Proc. Combust. Inst. 2000, 28, 2369-2374.

(68) Sadezky, A.; Muckenhuber, H.; Grothe, H.; Niessner, R.; Pöschl, U. Raman microspectroscopy of soot and related carbonaceous materials: Spectral analysis and structural information. Carbon 2005, 43, 1731-1742.

(69) Ferrari, A. C.; Robertson, J. Interpretation of Raman spectra of disordered and amorphous carbon. Phys. Rev. B: Condens. Matter Mater. Phys. 2000, 61, 14095.

(70) Senneca, O.; Apicella, B.; Russo, C.; Cerciello, F.; Salatino, P.; Heuer, S.; et al. Pyrolysis and Thermal Annealing of Coal and Biomass in CO2-Rich Atmospheres. Energy Fuels 2018, 32, 10701.

(71) Smith, M. W.; Pecha, B.; Helms, G.; Scudiero, L.; Garcia-Perez, $\mathrm{M}$. Chemical and morphological evaluation of chars produced from 
primary biomass constituents: Cellulose, xylan, and lignin. Biomass Bioenergy 2017, 104, 17-35.

(72) Borrego, A. G.; Garavaglia, L.; Kalkreuth, W. D. Characteristics of high heating rate biomass chars prepared under $\mathrm{N} 2$ and $\mathrm{CO} 2$ atmospheres. Int. J. Coal Geol. 2009, 77, 409.

(73) Gil, M. V.; Riaza, J.; Álvarez, L.; Pevida, C.; Rubiera, F. Biomass devolatilization at high temperature under $\mathrm{N} 2$ and $\mathrm{CO}$ 2: Char morphology and reactivity. Energy 2015, 91, 655. 